\title{
Antifungal activities of neem leaf extracts on the growth of Macrophomina phaseolina in vitro and its chemical characterization
}

\author{
Sumati Choudhary, A K Dwivedi, Pooja Singh* \\ Department of Botany, Deen Dayal Upadhyaya Gorakhpur University, Gorakhpur, 273009, Uttar Pradesh, \\ India
}

\begin{abstract}
The efficacy of different extracts of neem leaf on soil borne fungi M. phaseolina and chemical characterization of the neem leaf extracts were studied in vitro on the culture medium. The growth of $M$. phaseolina was inhibited significantly and controlled with both alcoholic and water extract of all ages and of the concentrations used. The alcoholic extracts of neem leaf was most effective (62.1 and 64.8\%) in comparison to aqueous extract (40.0 and 61.1\%) for retarding the growth of M. phaseolina. The identification of active component was done by comparing the retention time $\left(R_{t}\right)$ and chromatographic peaks of sample of Azadirachta indica leaves with their active component Azadirachtin. The gas chromatography fingerprint profile of the sample of Azadirachta indica leaves showed major peaks at the retention time of $9.82 \mathrm{~min}$ whereas, the pure standard of azadirachtin showed major peaks at the retention time $9.74 \mathrm{~min}$.
\end{abstract}

Kewords: Antifungal, Azadirachtin, Gas chromatography, Macrophomina phaseolina, Neem.

\section{Introduction}

Neem (Azadirachta indica A. Juss) is one of the very few trees known in the Indian subcontinent. This tree is belonged to Meliceae family and grows rapidly in the tropic and semi-tropic climate. It is also observed that this tree could survive in very dry and arid conditions. Neem tree is an evergreen tree, but it may become leafless for a short period in certain conditions [1]. Its leaves can be used as drug for diabetes, eczema and reduce fever. Every part of neem tree have been known to possess a wide range of pharmacological properties, especially as antibacterial, antifungal, antiulcer, antifeedant, repellent, pesticide, inhibitor and sterilant and is thus commercially exploitable and hence, traditionally used to treat large number of diseases. This eco-friendly native tree of India is perhaps most researched tree in the world. Water soluble extract of $A$. indica leaves was found to possess significant hypoglycemic, hypolipidemic, hepatoprotective, anti-fertility and hypotensive activities [2]. The earliest Sanskrit medical writings refer to the benefits of neem's fruit, seeds, oil, leaves, roots and bark. Each has been used in the Indian Ayurvedic and Unani medicine and is now being used in pharmaceutical and cosmetics industries [3]. It has great potential in the fields of pest management, environment protection and medicine. Neem is a natural source of insecticides, pesticides and agrochemicals [4] . Azadirachtin exhibited feeding and growth disruptive effect in some insects. Nimbidin exerted antiulcer, antiinflammatory, antipeptic and antisecretory effects in rats. An acetone extract of the leaves showed CNS depressant, positive inotropic and blood pressure lowering effects. Plant extract showed antifungal activity against some soil borne pathogens of cicer arietinum [5]. A large number of chemicals have been developed for the control of plant diseases. But due to overgrowing awareness of the hazardous side effects of these chemicals, more and more emphasis is being given to the use of biocontrol agents. Now major challenge is felt in the field of plant pathology to introduce some ecofriendly and safe alternative control strategies for agriculture, which led researchers to turn their attention to plants and microorganisms as a biocontrol agents. As the source of biocontrol agents neem has already emerged at the top of the list of plants with the highest potential. The following species of neem trees of Meliaceae family have been the subject of botanical biocontrol research: Azadirachta indica, A. Juss., A. excelsa Jack, A. siamens Valeton, Melia azadirachta L., M toosendon Sicb. and Zucc. and M. volkensii Gurke. The Meliaceae specially A. indica (Indian neem tree), contains at least 35 biologically active principals of Nimbin and azadirachtin [6] are the most active insecticidal ingradients and are present predominantly in the seeds, leaves and other parts of the neem tree [7].

In this study the effect of leaf extracts of various ages of neem leaves along with different extractants, on in vitro culture medium of M. phaseolina were studied and subsequent chemical characterization of the neem leaf extracts were mediated for its antifungal activity. 


\subsection{Preparation of plant extracts}

\section{Materials And Methods}

Juvenile and mature leaves were collected separately from Azadirachta indica plants growing in University campus, Gorakhpur university (2012-2013). For antifungal and secondary metabolite studies fresh leaves of 2-4 days old and 7-9 days old were collected during emergence time (February-March). Collected fresh leaves of Azadirachta indica (Neem) were washed thoroughly in running tap water and then ground in distilled water $(100 \mathrm{gm} / 100 \mathrm{ml})$. The macerate was filtered through double layered cheese cloth and centrifuged at 3,500 rpm for 20 minute. The supernatant was collected and served as plant extracts.

\subsection{In vitro evaluation of plant extracts against M. phaseolina}

Inhibitory effect of plant extract was assessed using poisoned food technique [8]. Appropriate amount of the extracts were separately mixed with molten PDA to get final concentration of 5, 10 and $20 \%$ of the extracts. The medium was then poured aseptically in to sterile Petri plates. Mycelial discs of $5 \mathrm{~mm}$ dia from 7day old actively growing culture of $M$. phaseolina were transferred to the centre of the solidified surface of the medium in individual plate. Control plates were also maintained where the culture discs were grown under the same conditions on PDA without extracts. Petri plates were incubated at $28 \pm 2^{\circ} \mathrm{C}$. Each treatment was replicated thrice. Observations were taken when growth in control covered entire Petri plate. The percent inhibition in mycelial growth over control was calculated.

Where,

$$
I=\frac{C-T}{C} \times 100
$$

$\mathrm{I}=$ Percent Inhibition

$\mathrm{C}=$ Colony diameter in Control

$\mathrm{T}=$ Colony diameter in Treatment

Table1. Antifungal activities of neem leaves by inhibition of mycelial growth of M. phaseolina

\begin{tabular}{|l|l|r|r|r|c|}
\hline Nature of leaf extract & \multirow{2}{*}{ Ages of leaf } & \multicolumn{4}{|c|}{ Inhibition of growth (\%)* } \\
\cline { 3 - 6 } & & $\mathbf{5}$ & $\mathbf{1 0}$ & $\mathbf{2 0}$ & Mean \\
\hline \multirow{2}{*}{ Alcoholic extracts } & Young 2-4 days & 44.0 & 67.0 & 75.2 & 62.1 \\
\cline { 2 - 6 } & Mature 7-9 days & 46.9 & 69.5 & 78.0 & 64.8 \\
\hline \multirow{2}{*}{ Water extracts } & Young 2-4 days & 0.0 & 53.0 & 67.0 & 40.0 \\
\cline { 2 - 6 } & Mature 7-9 days & 45.0 & 65.1 & 73.2 & 61.1 \\
\hline Control (Without extract) & & 0.0 & 0.0 & 0.0 & 0.0 \\
\hline \multicolumn{2}{|c|}{} & \multicolumn{4}{|c}{7.14} \\
CD (P=0.05) & \multicolumn{5}{|c|}{7.74} \\
\hline
\end{tabular}

- Figure were angular transformed before analysis

\subsection{Isolation and Identification of Bioactive Compound \\ 2.3.1Column Chromatography \\ Preparation of crude extracts:}

$50 \mathrm{gm}$ of dried and crushed leaves of Azadirachta indica were weighed. $50 \mathrm{ml}$ ethanol was added in dried and crushed leaves of Azadirachta indica and leaved it over night. $30 \mathrm{ml}$ filterate from the well crushed paste was transferred in to a separate conical flask through funnel. The ethanolic extract of leaves of Azadirachta indica was subjected to silica gel (60-120 mesh, Qualigens glass, Precious Electrochemindus Private limited, Mumbai, India) chromatography through 5 x $45 \mathrm{~cm}$ column. Five milliliter fractions of 60 elutents was eluted with $99.9 \%$ ethanol for each column preparations. Ethanol was evaporated under vacuum and the remaining solids obtained from the $5 \mathrm{ml}$ elutent were used for the determination of fungicidal activity.

\subsubsection{Thin Layer Chromatography}

Thin Layer Chromatography (TLC) was performed by the method of Jaiswal and Singh (2008) to identify the active fungicidal component present in the leaves of Azadirachta indica. TLC was done on $20 \mathrm{X}$ $20 \mathrm{~cm}$ precoated silica gel Precious Electrochemicals Private limited, Mumbai, India) using benzene/ethyl acetate $(9: 1, \mathrm{v}: \mathrm{v})$ as the mobile phase. Spots of column purified fractions of Leaves of Azadirachta indica along with their respective component was applied on TLC plates with a micropipette. Further, the TLC plate was developed by $\mathrm{I}_{2}$ vapour. Copy of chromatogram was made by tracing the plate immediately and retardation factor $\left(\mathrm{R}_{\mathrm{f}}\right)$ was calculated by using the following formula:

$\mathrm{R}_{\mathrm{f}}=$ distance travelled by centre of component/

Distance traveled by solvent front

$R_{\mathrm{f}}$ values signifies the retention factor i.e., more the molecular weight the more will be the distance travelled by the isolates. 


\subsubsection{Gas Chromatography}

Sample preparation

The filtrate of Leaves of Azadirachta indica was then concentrated to $1 \mathrm{ml}$ by bubbling nitrogen gas in to the solution and $2 \mu \mathrm{l}$ sample of the solution was employed in GC analysis. The GC analysis was carried out using a Clarus 500 perkin- elmer (Auto system XL) Gas Cromatograph equipped and coupled to a mass detector Turbo mass gold-Perkin Elmer Turbomass 5.1 spectrometer with an Elite-1 (100\% Dimethyl poly siloxane), $30 \mathrm{~m} \times 0.25 \mathrm{~mm}$ ID $\times 1 \mu \mathrm{m}$ of capillary column. The instrument was set to an initial temperature $110^{\circ} \mathrm{C}$, and maintained at this temperature for $2 \mathrm{~min}$. At the end of this period the oven temperature was rose up to $280^{\circ} \mathrm{C}$, at the rate of an increase of $5^{\circ} \mathrm{C} / \mathrm{min}$, and maintained for $9 \mathrm{~min}$. Injection port temperature was ensured as $250^{\circ} \mathrm{C}$ Helium flow rate as one $\mathrm{ml} / \mathrm{min}$. The ionization voltage was $70 \mathrm{Ev}$. The samples were injected in split mode as $10: 1$.

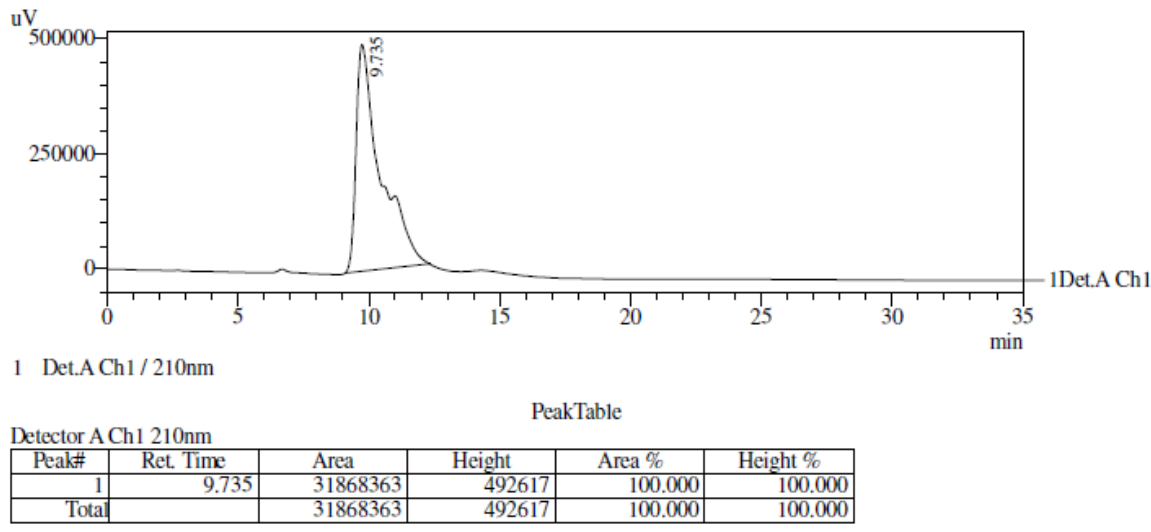

Figure1. Gas chromatogram of standard of Azadirachtin

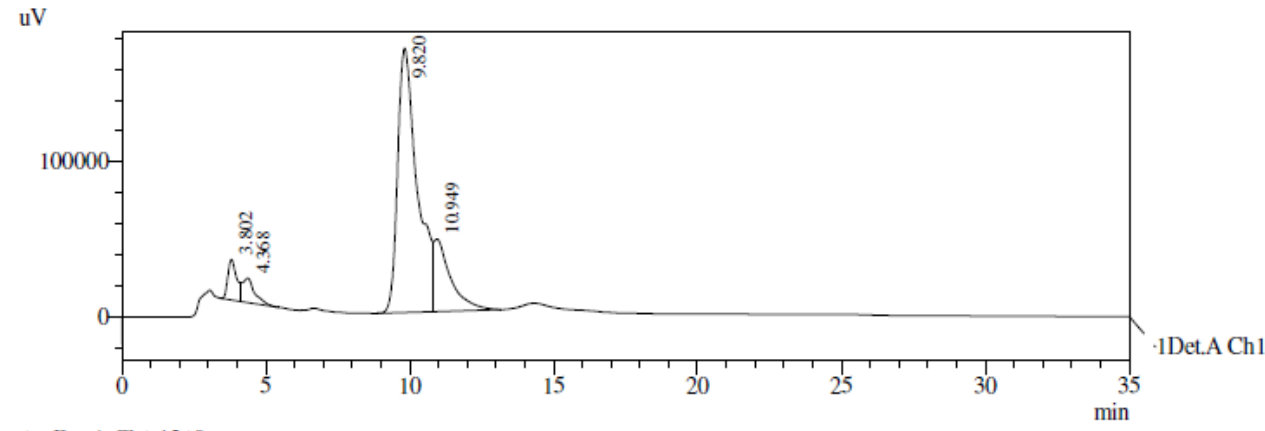

1 Det.A Ch1 /210nm

Detector A Ch1 210nm
\begin{tabular}{|r|r|r|r|r|r|}
\hline \multicolumn{1}{|c|}{ Peak\# } & Ret. Time & \multicolumn{1}{|c|}{ Area } & Height & Area \% & Height \% \\
\hline 1 & 3.802 & 577854 & 26138 & 5.219 & 10.077 \\
\hline 2 & 4.368 & 452723 & 15670 & 4.089 & 6.041 \\
\hline 3 & 9.820 & 8123485 & 170791 & 73.370 & 65.844 \\
\hline 4 & 10.949 & 1917895 & 46789 & 17.322 & 18.038 \\
\hline Total & & 11071957 & 259388 & 100.000 & 100.000 \\
\hline
\end{tabular}

Figure2. Gas chromatogram of sample of Azadirachtin

\subsection{In vitro tests}

III. Results

Results of present investigation shows that the growth of M. phaseolina was inhibited with the crude aqueous and alcoholic extract of different aged leaves of Azadirachta indica "Table-1". From the result it is evident that the inhibition of growth of fungus was more pronounced with the ethanolic leaf extracts as compared to aqueous leaf extracts. Significant inhibition of growth of M. phaseolina was observed in the artificial culture media containing older leaf extracts of Azadirachta indica. Of the concentration of aqueous and alcoholic leaf extracts of different aged leaves it was observed that higher concentrations leaf extracts were more effective on the growth inhibition of M. phaseolina "Table-1". 


\subsection{Chemical characterization of Neem Isolates}

Elutents which were collected through column chromatography were tested for fungicidal activity. After toxicity test it was found that in the leaves of Azadirachta indica, elutent nos. 22-30 were highly toxic against the M. phaseolina.

The thin layer chromatography analysis demonstrated that the $\mathrm{R}_{f}$ value of azadirachtin $(0.54)$ were equivalent to the $\mathbf{R}_{f}$ value of column- purified fractions of leaves of Azadirachta indica (0.54). Other spots could not be identified due to lack of standards.

The gas chromatography fingerprint profile of the sample of Azadirachta indica leaves showed major peaks at the retention time of $9.82 \mathrm{~min}$ (Fig.2) whereas, the pure standard of azadirachtin showed major peaks at the retention time 9.74 min "Fig. 1 ".

\section{Discussion}

The efficacy of different extracts of neem against the growth of M. phaseolina was treated in vitro and chemical characterization of the neem leaf extracts were mediated by column, TLC and gas chromatography.The present results of this investigation exhibits the radial growth of $M$. phaseolina was inhibited in vitro by water and ethanolic leaf extracts of Azadirachta indica, suggesting the presence of antifungal substances in the plant tissue, which agreed with the results reported by other workers on different pathogens and plants $[10,11,12,13,14]$. The alcoholic leaf extract was more effective than the water extracts of neem. Other workers also evaluate the efficacy of various extracts of neem leaf on seed borne fungi Aspergillus and Rhizopus and results confirmed that growth of both the fungal species was significantly inhibited and controlled with both alcoholic and water extract. Furthermore, alcoholic extract of neem leaf was most effectiveas compared to aqueous extract for retarding the growth of both fungal species [15]. Another finding showed the antimicrobial role of aqueous extracts of neem cake in the inhibition of spore germination against three sporulating fungi such as $C$. lunata, $H$. pennisetti and $C$. gloeosporioides f. sp. Mangiferae [16] and results of the study revealed that methanol and ethanol extract of Azadirachta indica showed growth inhibition against Aspergillus flavus, Alternaria solani and Cladosporium [17]. Aqueous extracts of various parts of neem such as neem oil and its chief principles have antifungal activities and have been reported by earlier investigators [ 18,19]. A study was undertaken to examine the antifungal activity of Azadirachta indica L. against Alternaria solani Sorauer and results confirmed that ethyl acetate fraction was found most effective in retarding fungal growth with MIC of $0.19 \mathrm{mg}$ and this fraction was also effective than fungicide (metalaxyl + mancozeb) as the fungicide has MIC of $0.78 \mathrm{mg}$ [20]. It was also observed that the mature leaf (7-9 days old) extracts have more inhibitory effect than that of young (2-4 days old) one. The differences in the toxicity of different extracts could be attributed to the presence of the active principles that are extracted by different solvents, which may be influenced by several factors such as age of plant, method of extraction and type of extracting solvent $[21,12]$. The greater effectiveness of ethanolic as compared with water extract of the neem leaf may be due to differences in constituent extraction [22]. It has been previously reported that the active ingredients of neem constitute mostly of triterpenoids, eg, Nimbin, Nimbidine, Azadirachtin etc. [23]. In the present study the thin layer chromatography analysis demonstrated that the $\mathrm{R}_{f}$ value of azadirichtin (0.54) were equivalent to the $\mathrm{R}_{f}$ value of column- purified fractions of leaves of Azadirachta indica (0.54) and also in gas chromatography fingerprint profile of the sample of Azadirachta indica leaves showed major peaks at the retention time of 9.82 min whereas, the pure standard of azadirichtin showed major peaks at the retention time $9.74 \mathrm{~min}$. Other compound could not be identified due to lack of standards.

\section{Conclusion}

Therefore, from the foregoing discussion it may be concluded that Azadirachta indica, a common medicinal plant could be exploited as the source of a potent biocide that have immense fungitoxic effect to several fungal pathogens like M. phaseolina.

\section{References}

[1]. H.S. Puri, Neem- The Divine Tree, (Harwood Acedemic Publisher, Amsterdam,1999)

[2]. A A Mamdouh and Mousa et al., Effect of neem leaf extract on fresh water fishes and Zooplanton community, $8^{\text {th }}$ International Symposium on Tilapia in Aquaculture, 2008.

[3]. B Brototi and R. D. Kaplay, Azadirachta indica (Neem): It's economic utility and chances for commercial planned plantation in Nanded District, Int. J. Pharma 1(2), 2011, 100-104.

[4]. K Girish et al. Neem- A Green Treasure, Electronic Journal of Biology 4(3), 2008,102-111.

[5]. S Singhal and M. Bhatt, Review on a natural drugstore-Neem, World Journal of Pharmacy and Pharmaceutical Sciences 5 (8), 2016, 379-396.

[6]. T D Pennington, Flora Neotropica, New York Botanical Garden, NY, Monogr. No.28, 1981

[7]. M S Mulla and T. Su, J.Am. Mosq. Control Assoc. 15(2), 1999,133-152.

[8]. J Singh and N. N. Tripathi, Inhibition of storage fungi of blackgram (Vigna mungo L.) by some essential oils, Flavour and Fragrance Journal 14, 1999, 1-4. 
[9]. P Jaiswal and D.K. Singh, Molluscicidal activity of Carica papaya and Areca catechu against the french water snail Lymnaea acuminate, Veterinary Parasitology 15(2), 2008, 264-270.

[10]. S N Tewari and M. Nayek, Activity of four plant leaf extracts against three fungal pathogen of rice, Trap. Agric. (Trinidad) 68, $1991373-375$.

[11]. A S Al-Abed, J.R. Quasem and H.A. Abu-Blam, Antifungal effects of some common wild plants species on certain plant pathogenic fungi, Dirasat (Pure and Applied Science) 20, 1993, 149-158.

[12]. J R Quasem and H.A. Abu-Blam, Fungicidal activity of some common weed extracts against different plant pathogenic fungi, Journal of Phytopathology 14(4), 1996, 157-161.

[13]. A C Amadioha, Fungitoxic activity of extracts of Azadirachta indica and Xylopia aethiopica on Colletotrichum lindemuthianum in Cowpea, Journal of Herbs, Spices and Medicinal plants 6, 1998, 33-40.

[14]. A C Amadioha, Fungitoxic effects of extracts of Azadirachta indica against Cochliobolus miyabeanus causing Brown spot disease of Rice, Acta. Phytopath. Pflanz ,35, 2003, 37-42.

[15]. N K Mondali, A. Mojumdar, S.K. Chatterje, A. Banerjee, J.K.Dutta, S. Gupta, Antifungal activities and chemical characterization of neem leaf extracts on the growth of some selected fungal species in vitro culture medium, Journal of Applied Sciences and Environmental Management ,13(1), 2009: 49-53.

[16]. K Anjali, K. Ritesh, M. Sudarshan, S.C. Jaipal and S. Kumar, Antifungal efficacy of aqueous extract of neem cake, karanj cake and vermicompost against some phytopathogenic fungi, The Bioscan 8, 2013, 671-674.

[17]. D K Srivastava and K. Swarnkar, Antifungal activity of leaf extract of neem (Azadirachta indica Linn), International Journal of Current Microbiology and Applied Sciences, 3, 2014, 305-308.

[18]. V Natarajan, P.V. Venugopal and T. Menon, Effect of Azadirachta indica (Neem) on the growth pattern of dermatophytes, Indian Journal of medical Microbiology, 21(2), 2003, 98-102.

[19]. C A C Llyod, T. Menon and K. Uma Maheswari, Anticandial activity of Azadirachta indica, Indian Journal of Pharmacology 37(6), 2005, 386-389.

[20]. K Jabeen, S. Hanif, S. Naz and S. Iqbal, Antifungal activity of Azadirachta indica against Alternaria solani,, Journal of Life Sciences and Technologies 1(1), 2013, 89-93.

[21]. J R Nicolls, Antifungal activity in Passiflora species, Annals. Hot 34, 1969, 229-237.

[22]. P S Shekhawrat, and R. Prasada, Antifungal properties of some plant extracts: Inhibition of spore germination, Indian Phytopathology,24, 1991 800-802.

[23]. G Brahmachari, Neem-An Omnipotent Plant: A Retrospection, Chem bio Chem (Wiley-VCH) 5, $2004,408-421$. 